\title{
Hypomethylation of the Toll-like receptor-2 gene increases the risk of essential hypertension
}

\author{
SHUQI MAO ${ }^{1 *}$, TIANLUN GU $^{1 *}$, FADE ZHONG $^{2}$, RUI FAN $^{1}$, \\ FUBAO ZHU ${ }^{3}$, PEIPEI REN ${ }^{4}$, FENGYING YIN ${ }^{5}$ and LINAZHANG ${ }^{1}$
}

\begin{abstract}
${ }^{1}$ Department of Preventive Medicine, Zhejiang Provincial Key Laboratory of Pathophysiology, School of Medicine, Ningbo University; ${ }^{2}$ The Central Blood Station of Ningbo, Ningbo; ${ }^{3}$ Health and Family Planning Commission of Zhenhai, Ningbo; ${ }^{4}$ Clinical Laboratory, Baizhang Street Community Health Service Center of JiangDong, Ningbo, Zhejiang 315211;

${ }^{5}$ Clinical Laboratory, The First Hospital of Ningbo, Ningbo, Zhejiang 315010, P.R. China
\end{abstract}

Received April 13, 2016; Accepted March 13, 2017

DOI: $10.3892 / \mathrm{mmr} .2017 .6653$

\begin{abstract}
Studies on the etiology of essential hypertension (EH) have demonstrated that chronic inflammation contributes to the onset and development of elevated blood pressure. Toll-like receptors (TLRs), important immune receptors, serve a role in chronic inflammation and are associated with EH. In the present study, 96 patients with $\mathrm{EH}$, and 96 age- and sex-matched healthy controls were recruited, and eight cytosine-phosphate-guanine $(\mathrm{CpG})$ dinucleotides (CpG1-8) were analyzed using bisulfite pyrosequencing technology. It was observed that the methylation levels of all of the eight $\mathrm{CpG}$ dinucleotides were decreased in the EH group compared with the control group; however, only CpG1 (2.83 \pm 1.34 vs. $3.44 \pm 1.75 ; \mathrm{P}=0.009)$, CpG6 (3.58 \pm 3.64 vs. $8.30 \pm 4.13 ; \mathrm{P}<0.001)$ and $\mathrm{CpG} 8(8.91 \pm 5.32$ vs. $11.33 \pm 3.87$; $\mathrm{P}<0.001)$ were significantly different, as demonstrated by paired t-test analysis. In addition, logistic regression analysis demonstrated that $\mathrm{CpG6}$ hypomethylation was a risk factor of $\mathrm{EH}$ (odds ratio=1.10; adjusted $\mathrm{P}=0.009$ ), and $\mathrm{CpG6}$ methylation level was observed to be negatively correlated with systolic blood pressure $(\mathrm{r}=-0.304 ; \mathrm{P}<0.001)$ and diastolic blood pressure $(\mathrm{r}=-0.329 ; \mathrm{P}<0.001)$. Additionally, receiver operating characteristic curve analysis demonstrated that a methylation level of $7.5 \%$ for CpG6 (area under the curve,
\end{abstract}

Correspondence to: Mrs. Lina Zhang, Department of Preventive Medicine, Zhejiang Provincial Key Laboratory of Pathophysiology, School of Medicine, Ningbo University, 818 Fenghua Road, Ningbo, Zhejiang 315211, P.R. China

E-mail: zhanglina@nbu.edu.cn

Mrs. Fengying Yin, Clinical Laboratory, The First Hospital of Ningbo, 59 Liuding Street, Ningbo, Zhejiang 315010, P.R. China E-mail: yfyno1@foxmail.com

*Contributed equally

Key words: essential hypertension, DNA methylation, Toll-like receptor-2, gene promoter, epigenetic
$0.834 ; \mathrm{P}<0.001$ ) was an appropriate threshold value to predict the risk of $\mathrm{EH}$. With generalized multifactor dimensionality reduction, a potential gene-gene interaction between CpG6 and $\mathrm{CpG} 8(\mathrm{P}=0.001)$, and gene-environment interactions between smoking, alcohol consumption, $\mathrm{CpG} 6, \mathrm{CpG} 7$ and CpG8 ( $\mathrm{P}=0.011)$, were observed. In conclusion, the results of the present study demonstrated that hypomethylation of the $T L R 2$ promoter, particularly CpG6, was associated with the risk of $\mathrm{EH}$ in this population. Additionally, a gene-gene interaction between $\mathrm{CpG} 6$ and $\mathrm{CpG} 8$, and interactions between environmental factors, including smoking and alcohol consumption, and $\mathrm{CpG} 6, \mathrm{CpG} 7$ and $\mathrm{CpG} 8$, may be associated with the risk of $\mathrm{EH}$.

\section{Introduction}

Essential hypertension (EH) is a risk factor for cardiovascular diseases and organ damage, which has become a major cause of morbidity and mortality worldwide (1). The World Health Organization (Geneva, Switzerland) has reported that $29.2 \%$ of the global population will develop hypertension by 2025, and the prevalence in China was observed to be $26.7 \%$ in 2010 (2). Although the etiology of EH remains unclear, previous studies have indicated that low-grade chronic inflammation is a hallmark of EH and contributes to target organ damage and the development of atherosclerosis, which is a process mediated by circulating immune cells, particularly leucocytes (3-5).

Toll-like receptors (TLRs), members of the interleukin (IL) 1R superfamily, are transmembrane receptors with extracellular leucine-rich repeats and an important intracellular signaling domain. TLRs are expressed in monocytes, macrophages and neutrophils, and recognize pathogen-associated molecular patterns to initiate an innate immune response. TLR2 serves a role in endothelial cell activation, macrophage recruitment and pro-inflammatory cytokine production. In TLR2 signaling, TLR2 dimerizes with TLR1 or TLR6. The heterodimers recruit and activate interleukin-1 receptor-associated kinase 4 via a myeloid differentiation primary response protein MyD88 (MyD88)/MyD88 adaptor-like (Mal)-dependent mechanism, and therefore facilitate the induction of cytokines (6-8). 
Previously, elevated circulating pro-inflammatory cytokine markers related to the TLR signaling pathway, including tumor necrosis factor (TNF)- $\alpha$, C-reactive protein (CRP) and IL-6, were hypothesized to be important risk factors for $\mathrm{EH}(4,9)$. TLRs have been suggested to serve a role in the pathogenesis of EH $(10,11)$ and atherosclerotic diseases (12-14). However, the underlying mechanisms that regulate this response remain unclear.

An important mechanism of epigenetic regulation, DNA methylation is reversible and primarily occurs at cytosine residues in cytosine-phosphate-guanine $(\mathrm{CpG})$ dinucleotides, in mammalian cells (15). Gene promoter hypermethylation silences gene expression, while promoter hypomethylation promotes active transcription (16). Previous studies into the etiology of EH have focused on DNA methylation. ADD1, AGTR1 and GCK gene methylation have been demonstrated to be associated with EH (17-19). Alexeeff et al (9) reported that the aberrant methylation of $T L R 2$, inducible nitric oxide synthase and interferon $-\gamma$ was associated with blood pressure.

However, the association of TLR2 methylation with EH remains unclear. The present study aimed to investigate whether TLR2 promoter methylation was associated with $\mathrm{EH}$ and to assess the association of TLR2 promoter methylation with age, blood pressure and other risk factors of $\mathrm{EH}$.

\section{Materials and methods}

Sample collection. A total of 192 individuals, including 96 healthy controls, and 96 newly-diagnosed patients with $\mathrm{EH}$ who had not received anti-hypertensive therapy, were recruited at Ningbo Seventh Hospital (Ningbo, China). Patients were defined as hypertensive according to the 'gold standard' diagnostic criteria, and exhibited $\geq 3$ consecutive measurements of systolic blood pressure (SBP) $>140 \mathrm{mmHg}$ and/or diastolic blood pressure (DBP) $>90 \mathrm{mmHg}$ (20). Controls exhibited SBP $<120 \mathrm{mmHg}$ and DBP $<80 \mathrm{mmHg}$, and reported no family history of hypertension in first degree relatives. All of the participants were from Han Chinese families who had been residing in Ningbo for $\geq 3$ generations, with no history of secondary hypertension, diabetes mellitus, stroke, renal failure, myocardial infarction, drug abuse, or other serious diseases.

A calibrated mercury sphygmomanometer with an adult-sized cuff was used to measure blood pressure based on the standard protocols of the American Heart Association (21). Blood pressure was measured twice in the supine position, $\geq 10 \mathrm{~min}$ apart by trained technicians. Blood samples were drawn from the antecubital vein using vacutainer tubes containing EDTA, and stored at $-80^{\circ} \mathrm{C}$ for DNA extraction. The protocol was approved by the ethics committee of Ningbo Seventh Hospital, and written informed consent was obtained.

Biochemical analyses. Plasma levels of triglyceride, total cholesterol, uric acid, high-density lipoprotein (HDL), low-density lipoprotein (LDL), alanine aminotransferase, serum creatinine and leucocytes were measured enzymatically using an AU2700 automatic analyzer (Olympus Corporation, Tokyo, Japan). A Lab-Aid 820 nucleic acid
Table I. Primers of the Toll-like receptor-2 cytosine-phosphate-guanine island sequence.

\begin{tabular}{ll} 
Primers & \multicolumn{1}{c}{ Sequence } \\
\hline Forward & 5'-Biotin-GGTAGTTGTAGGGGTAGGAT-3' \\
Reverse & 5'-ACCCAAAAAAACTCTAAACCTC-3' \\
Sequence & 5'-TTCCAAACAAATAACC-3' \\
\hline
\end{tabular}

extraction analyzer (Xiamen Zeesan Biotech Co., Ltd., Xiamen, China) was used to extract genomic DNA from peripheral blood samples. DNA concentration was measured using a NanoDrop 2000 ultra-micro nucleic acid ultraviolet tester (Thermo Fisher Scientific, Inc., Wilmington, DE, USA).

The sequencing-by-synthesis technique of pyrosequencing was used to measure methylation levels. DNA sequences were reacted with sodium bisulfite (EpiTech Bisulfite kit; Qiagen GmbH, Hilden, Germany) to convert unmethylated cytosine residues to thymine, and subsequently amplified by polymerase chain reaction (PCR) prior to being 'sequenced by synthesis' (Pyromark Gold Q96, Qiagen GmbH) (22). The CpG sites of target gene sequences and PCR primers were chosen according to the scores automatically calculated by the PyroMark Assay Design (version 2.0.1.15; Qiagen $\mathrm{GmbH}$ ) using previously established protocols for primer design (23). $\mathrm{CpG}$ island sequences were amplified using a Mastercycler Nexus Gradient (Eppendorf, Hamburg, Germany) in reactions containing $12 \mu \mathrm{l} \mathrm{ZymoTaq}^{\mathrm{TM}}$ Premix (Zymo Research Corporation, Irvine, CA, USA), $8 \mu$ l DNase/RNase-free $\mathrm{H}_{2} \mathrm{O}, 1.5 \mu \mathrm{l}$ each of forward and reverse primer and $2 \mu \mathrm{l}$ bisulfite-converted DNA. Reactions were first denatured at $95^{\circ} \mathrm{C}$ for $10 \mathrm{~min}$; amplified over 40 cycles at $95^{\circ} \mathrm{C}$ for $30 \mathrm{sec}$, $54.1^{\circ} \mathrm{C}$ for $40 \mathrm{sec}$ and $72^{\circ} \mathrm{C}$ for $50 \mathrm{sec}$; and extended at $72^{\circ} \mathrm{C}$ for $7 \mathrm{~min}$. TLR2 $\mathrm{CpG}$ island sequences were amplified with the primers presented in Table I.

Statistical analyses. Experimental data were analyzed using PASW statistics software (version 19.0; IBM SPSS, Armonk, NY, USA). Results are presented as the mean \pm standard deviation or number (percentage) of patients. Continuous variables, including DNA methylation, age, body mass index (BMI), total cholesterol, triglycerides, uric acid, HDL, LDL, serum creatinine and leucocyte count, were compared by paired t-test or nonparametric test. The Pearson $\chi^{2}$ or Fisher's exact test was used to analyze the association between categorical variables (sex, smoking and alcohol consumption) and essential hypertension. Pearson's correlation analysis was used to investigate interactions among the eight $\mathrm{CpG}$ sites in the TLR2 promoter sequence. Receiver operating characteristic (ROC) curves were used to determine the sensitivity of TLR2 promoter methylation as a predictor of EH. Logistic regression was implemented to adjust for confounding factors. Generalized multifactor dimensionality reduction (GMDR) was applied to investigate underlying high-order interactions between TLR 2 promoter methylation and risk factors of $\mathrm{EH} . \mathrm{P}<0.05$ was considered to indicate a statistically significant difference. 
Table II. Comparison of characteristics between controls and EH group.

\begin{tabular}{|c|c|c|c|c|}
\hline Characteristics & Controls & $\mathrm{EH}$ & $t(Z) / \chi^{2}$ & P-value \\
\hline Age $($ mean $\pm \mathrm{SD})$ & $56.3 \pm 8.2$ & $56.7 \pm 8.7$ & 0.32 & 0.747 \\
\hline Sex, male/female & $38 / 58$ & $38 / 58$ & $\mathrm{n} / \mathrm{a}$ & $\mathrm{n} / \mathrm{a}$ \\
\hline Smoking, yes/no & $79 / 17$ & $69 / 27$ & 2.95 & 0.086 \\
\hline Alcohol consumption, yes/no & $65 / 31$ & $56 / 40$ & 1.81 & 0.178 \\
\hline $\mathrm{BMI}($ mean $\pm \mathrm{SD})$ & $22.16 \pm 2.30$ & $23.6 \pm 3.09$ & 4.09 & $9.1 \times 10^{-5}$ \\
\hline $\mathrm{HDL}, \mathrm{mg} / \mathrm{dl}($ mean $\pm \mathrm{SD})$ & $7.99 \pm 6.32$ & $2.07 \pm 5.58$ & 6.57 & $2.6 \times 10^{-9}$ \\
\hline $\mathrm{LDL}, \mathrm{mg} / \mathrm{dl}($ mean $\pm \mathrm{SD})$ & $3.21 \pm 0.87$ & $3.31 \pm 0.68$ & 0.90 & 0.370 \\
\hline ALT, IU/1 (mean \pm SD) & $26.41 \pm 16.1$ & $28.27 \pm 12$ & 0.89 & 0.370 \\
\hline Triglyceride, $\mathrm{mmol} / \mathrm{l}($ mean $\pm \mathrm{SD})$ & $1.21 \pm 0.68$ & $1.43 \pm 0.72$ & 2.33 & 0.022 \\
\hline Total cholesterol, mmol/1 (mean \pm SD) & $5.19 \pm 0.89$ & $5.38 \pm 0.61$ & 1.71 & 0.091 \\
\hline Urea, mmol/1 (mean \pm SD) & $4.96 \pm 1.07$ & $5.03 \pm 1.11$ & 0.52 & 0.607 \\
\hline Uric acid, $\mu \mathrm{mol} / \mathrm{l}($ mean $\pm \mathrm{SD})$ & $300.32 \pm 73.15$ & $325.75 \pm 82.63$ & 2.75 & 0.007 \\
\hline Serum creatinine, $\mu \mathrm{mol} / \mathrm{l}($ mean $\pm \mathrm{SD})$ & $82.68 \pm 12.28$ & $83.46 \pm 11.04$ & 0.53 & 0.600 \\
\hline WBC count (mean \pm SD) & $5.59 \pm 0.93$ & $6.17 \pm 0.98$ & 4.84 & $1.30 \times 10^{-6}$ \\
\hline Lymphocyte count (mean \pm SD) & $1.98 \pm 0.61$ & $2.1 \pm 0.55$ & 2.05 & 0.040 \\
\hline Monocyte count $($ mean \pm SD) & $0.30 \pm 0.18$ & $0.31 \pm 0.17$ & 0.49 & 0.622 \\
\hline Neutrophil granulocyte count (mean \pm SD) & $3.05 \pm 0.97$ & $3.35 \pm 0.92$ & 2.55 & 0.011 \\
\hline Eosinophil granulocyte count (mean \pm SD) & $0.13 \pm 0.13$ & $0.129 \pm 0.10$ & 0.75 & 0.451 \\
\hline Basophil granulocyte count (mean \pm SD) & $0.15 \pm 0.64$ & $0.02 \pm 0.02$ & 0.66 & 0.508 \\
\hline
\end{tabular}

BMI, body mass index; HDL, high-density lipoprotein; LDL, low-density lipoprotein; ALT, alanine aminotransferase; EH, essential hypertension; SD, standard deviation; WBC, white blood cell; n/a, not applicable.

Table III. Logistic regression analysis of the methylation levels of the eight CpG sites.

\begin{tabular}{|c|c|c|c|c|c|c|}
\hline \multirow[b]{2}{*}{ Variables } & \multirow{2}{*}{$\begin{array}{c}\text { Controls } \\
(\text { mean } \pm \mathrm{SD})\end{array}$} & \multirow{2}{*}{$\begin{array}{c}\mathrm{EH} \\
(\text { mean } \pm \mathrm{SD})\end{array}$} & \multirow[b]{2}{*}{$\mathrm{t}$} & \multirow[b]{2}{*}{ P-value } & \multicolumn{2}{|c|}{ Controls vs. EH } \\
\hline & & & & & OR $(95 \% \mathrm{CI})$ & P-value ${ }^{a}$ \\
\hline CpG1 & $3.44 \pm 1.75$ & $2.83 \pm 1.34$ & 2.69 & 0.009 & $0.99(0.838 \sim 1.173)$ & 0.921 \\
\hline CpG2 & $1.93 \pm 1.84$ & $1.71 \pm 1.57$ & 0.97 & 0.336 & $0.91(0.715 \sim 1.146)$ & 0.408 \\
\hline CpG3 & $0.69 \pm 1.60$ & $0.58 \pm 1.80$ & 0.43 & 0.665 & $0.96(0.743 \sim 1.248)$ & 0.776 \\
\hline CpG4 & $1.65 \pm 2.08$ & $1.65 \pm 2.06$ & 0.00 & 1.000 & $1.07(0.883 \sim 1.305)$ & 0.478 \\
\hline CpG5 & $0.68 \pm 1.53$ & $0.66 \pm 1.80$ & 0.09 & 0.926 & $1.03(0.805 \sim 1.327)$ & 0.798 \\
\hline CpG6 & $8.30 \pm 4.13$ & $3.58 \pm 3.64$ & 8.31 & $6.5 \times 10^{-13}$ & $1.10(1.021 \sim 1.161)$ & 0.009 \\
\hline CpG7 & $3.51 \pm 3.90$ & $3.25 \pm 3.51$ & 0.51 & 0.613 & $0.99(0.893 \sim 1.103)$ & 0.889 \\
\hline CpG8 & $11.33 \pm 3.87$ & $8.91 \pm 5.32$ & 3.82 & $2.4 \times 10^{-4}$ & $0.98(0.939 \sim 1.025)$ & 0.389 \\
\hline
\end{tabular}

${ }^{a}$ Adjusted for age, gender, smoking, alcohol consumption, uric acid, serum creatinine, triglyceride, HDL (mg/dl) and BMI. CpG, cytosine-phosphate-guanine; EH, essential hypertension; SD, standard deviation; OR, odds ratio; CI, confidence interval.

\section{Results}

Characteristics of the 96 healthy controls and 96 patients with EH are presented in Table II. The age ( \pm 3 years) and sex ratio was matched in the participants between the two groups. In addition, as presented in Table II, BMI $\left(\mathrm{t}=4.09 ; \mathrm{P}=9.1 \times 10^{-5}\right)$, HDL $(\mathrm{t}=6.57$; $\left.\mathrm{P}=2.6 \times 10^{-9}\right)$, triglyceride $(\mathrm{t}=2.33 ; \mathrm{P}=0.022)$ and uric acid $(\mathrm{t}=2.75$; $\mathrm{P}=0.007$ ) were significantly different between the two groups.

In the present study, eight $\mathrm{CpG}$ sites were selected to investigate the association between methylation and $\mathrm{EH}$ in the
CpG island of the TLR2 gene promoter. Details of the eight CpG sites are presented in Fig. 1 and Table III. As presented in Table III and Fig. 2, eight CpG sites of the EH group exhibited decreased methylation levels compared with healthy controls; however, only CpG1 (2.83 \pm 1.34 vs. 3.44 $\pm 1.75 ; \mathrm{P}=0.009)$, CpG6 $(3.58 \pm 3.64$ vs. $8.30 \pm 4.13 ; \mathrm{P}<0.001)$ and $\mathrm{CpG} 8(8.91 \pm 5.32$ vs. $11.33 \pm 3.87 ; \mathrm{P}<0.001)$ were significantly different.

In order to adjust for confounding factors, logistic regression was applied to obtain the odds ratio (OR) of CpG1-8. As presented in Table III, when adjusted for age, gender, smoking, 
TLR2 (chr4:154605441-154627242)
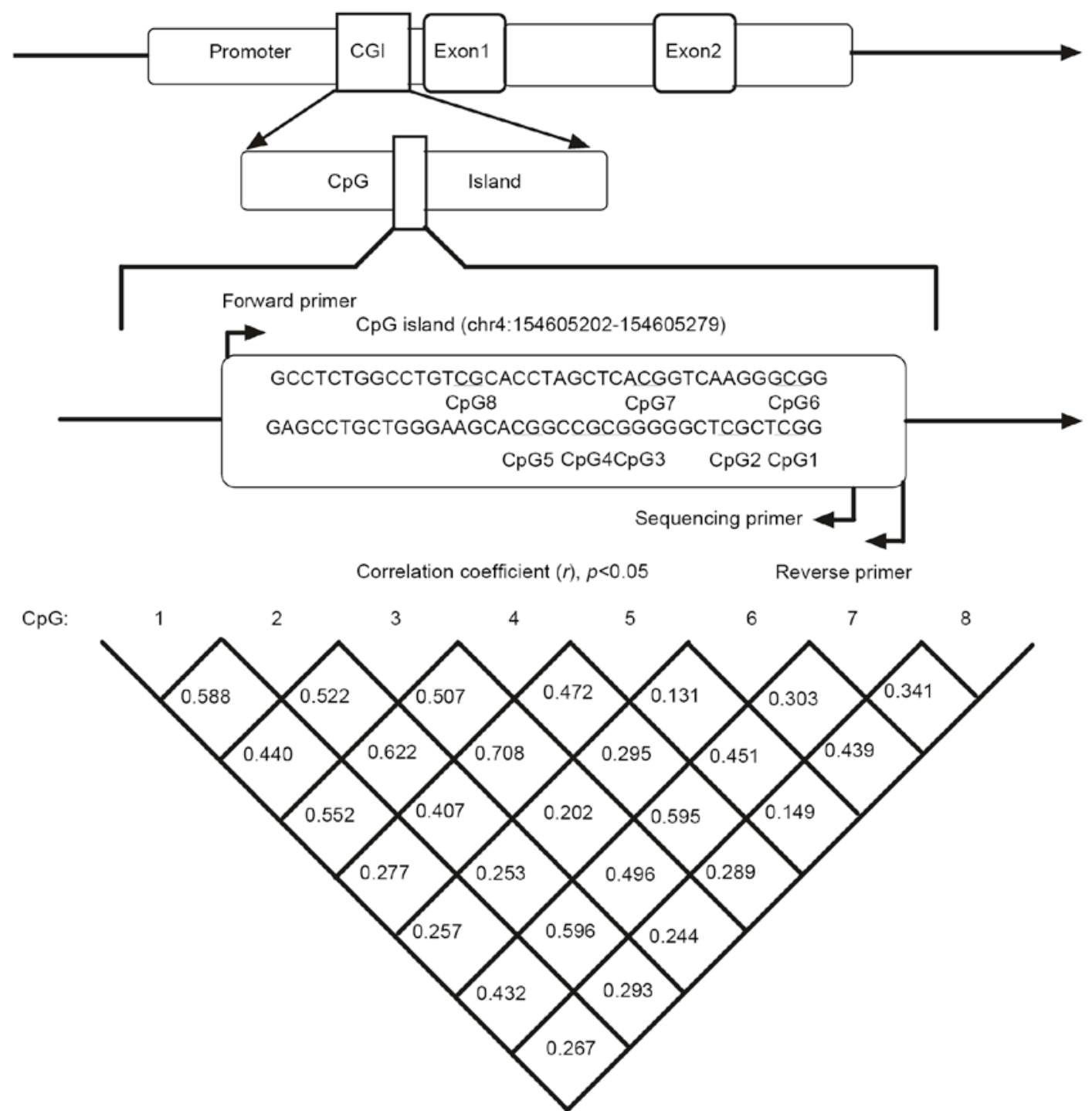

Figure 1. Correlation analysis between eight $\mathrm{CpG}$ sites in TLR2 promoter region. TLR2, Toll-like receptor-2; CpG, cytosine-phosphate-guanine; CGI, CpG island.

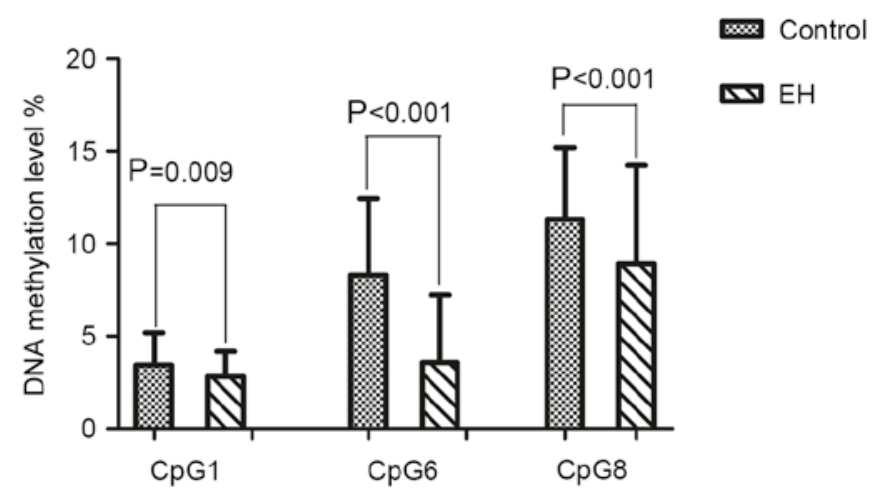

Figure 2. Analysis of CpG1, CpG6 and CpG8 site methylation. $\mathrm{CpG}$, cytosine-phosphate-guanine; EH, essential hypertension.

alcohol consumption, uric acid, serum creatinine, triglyceride, HDL and BMI, the results indicated that the methylation level of CpG6 was an important risk factor for $\mathrm{EH}(\mathrm{OR}=1.10$; adjusted $\mathrm{P}=0.009)$. Pearson correlation analysis demonstrated that the methylation level of CpG6 was negatively correlated with SBP $(r=-0.304 ; \mathrm{P}<0.001)$ and DBP $(\mathrm{r}=-0.329 ; \mathrm{P}<0.001)$ (Fig. 3).

ROC curve analysis was used to analyze the diagnostic value of CpG6 methylation to $\mathrm{EH}$. The results presented in Fig. 4 indicated that a methylation level of 7.5\% for CpG6 (area under the curve, 0.834; $\mathrm{P}<0.001$ ) was an appropriate threshold value to predict the risk of $\mathrm{EH}$.

GMDR was used to investigate high-order interactions between the methylation of $\mathrm{CpG}$ sites of the TLR2 promoter and other risk factors. The best models at various orders are summarized in Table IV. The two-order model between CpG6 and CpG8 is the best model of gene-gene interaction (testing balanced accuracy, 0.874; cross-validation consistency, 10/10; $\mathrm{P}=0.01$ ), and the five-order model among smoking, alcohol consumption, CpG6, CpG7 and CpG8 is the best model of gene-environment interaction (testing balanced accuracy, 0.985; cross-validation consistency, $8 / 10 ; \mathrm{P}=0.01$ ). 
Table IV. Generalized multifactor dimensionality reduction models of essential hypertension and high-order interactions among CpG sites in the Toll-like receptor-2 promoter.

\begin{tabular}{lccr}
\hline Model & $\begin{array}{c}\text { Testing balanced } \\
\text { accuracy }\end{array}$ & $\begin{array}{c}\text { Cross-validation } \\
\text { consistency }\end{array}$ & $\begin{array}{r}\text { Sign test } \\
\text { (P-value) }\end{array}$ \\
\hline CpG8 & 0.762 & $10 / 10$ & $10(0.001)$ \\
CpG6-CpG8 & 0.874 & $10 / 10$ & $10(0.001)$ \\
CpG1-CpG6-CpG8 & 0.917 & $8 / 10$ & $10(0.001)$ \\
Alcohol consumption-CpG6-CpG7-CpG8 & 0.945 & $7 / 10$ & $9(0.011)$ \\
Smoking-alcohol consumption-CpG6-CpG7-CpG8 & 0.985 & $8 / 10$ & $9(0.011)$ \\
\hline
\end{tabular}

CpG, cytosine-phosphate-guanine.
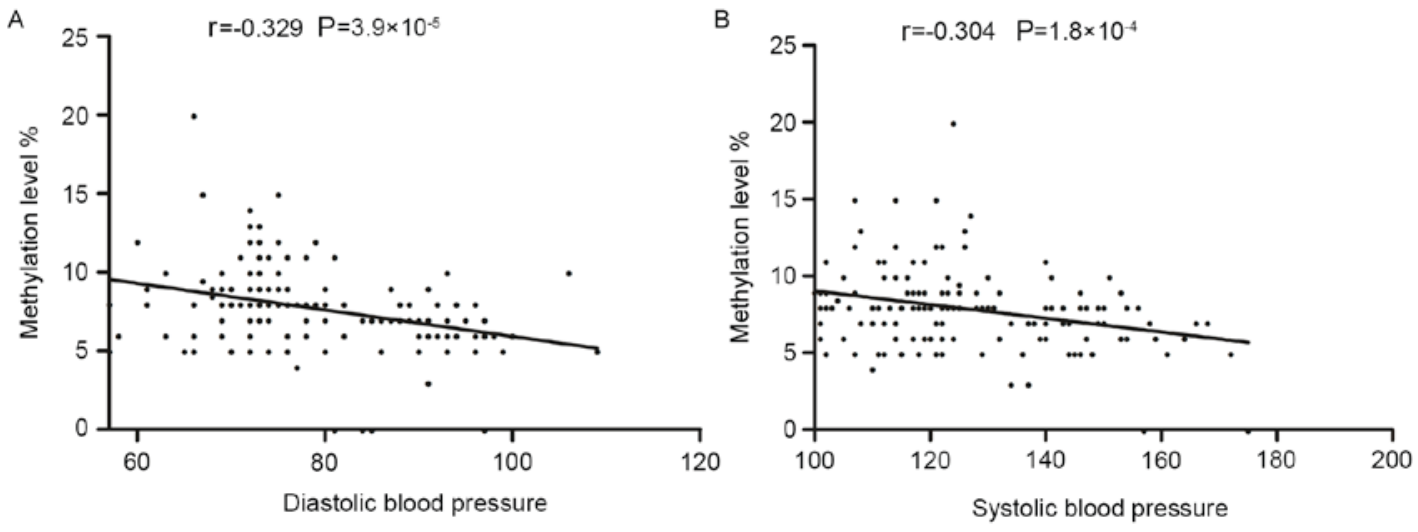

Figure 3. Pearson correlation analysis between cytosine-phosphate-guanine 6 site methylation and (A) diastolic and (B) systolic blood pressure.

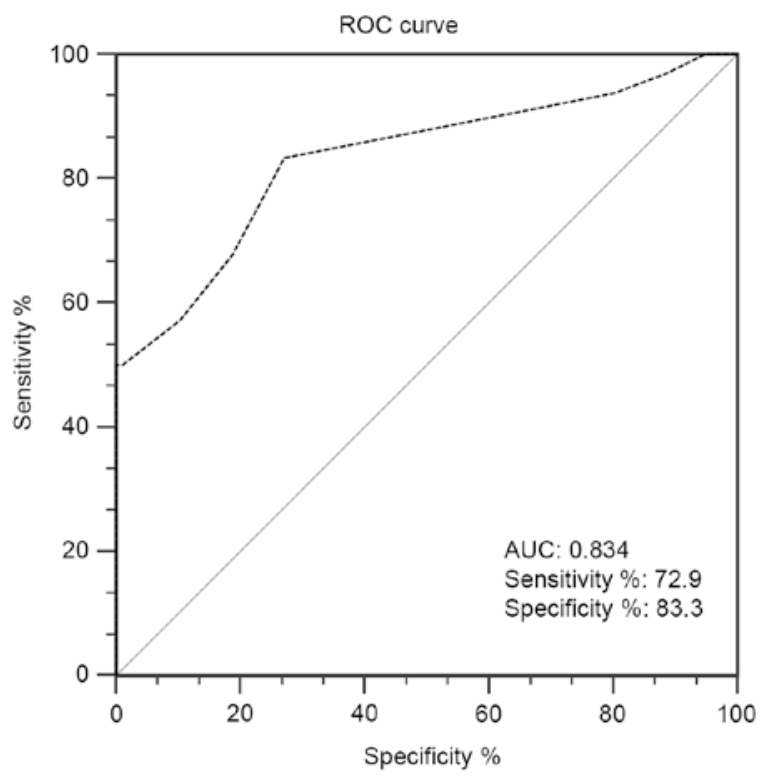

Figure 4. ROC analysis of the cytosine-phosphate-guanine 6 site in the diagnosis of essential hypertension. ROC, receiver operating curve; AUC, area under the curve.

\section{Discussion}

Previous studies have demonstrated that TLR2 activation may induce nicotinamide-adenine dinucleotide phosphate oxidase to produce reactive oxygen species in monocytes and macrophages (24-26), and endothelial TLR2 signaling may result in inhibition of endothelial NO bioavailability (27). TLR2 dimers with TLR1 or TLR6 may lead to the upregulation of cytokines by a MyD88/Mal and nuclear factor (NF)- $\kappa \mathrm{B}$ pathway-dependent mechanism. One such control may be at the level of TLR expression itself. However, the underlying molecular mechanisms remain unknown.

By investigating TLR2 gene promoter methylation, the present study demonstrated that $T L R 2$ gene promoter methylation levels were decreased in patients with EH compared with healthy controls, particularly the CpG1, CpG6 and CpG8 sites. The hypomethylation of CpG6 hypomethylation was demonstrated to be a risk factor of EH. Previous studies have demonstrated that the methylation of gene promoters silences the transcription of the genes (28-30), and that an alteration in CpG methylation may influence gene expression via directly interfering with transcription factor-binding complexes or by histone modifications mediated by methyl-CpG-binding proteins $(31,32)$. Therefore, the results of the present study suggest that hypomethylation of the TLR2 gene promoter is likely to increase the expression of the TLR2 gene and enhance pro-inflammatory responses in EH. Shuto et al (33) have reported that promoter hypomethylation of the TLR2 gene is associated with an increased pro-inflammatory response and that TLR2 expression is epigenetically upregulated in cystic fibrosis bronchial epithelial cells. In a 
study of periodontitis, Benakanakere et al (34) observed that hypermethylation of the TLR2 promoter was able to diminish $T L R 2$ and pro-inflammatory cytokine expression in response to infection with Porphyromonas gingivalis. Previous results from DNA methylation profiles of patients with Keshan disease compared with normal individuals demonstrated that selenium deficiency led to decreased methylation of $\mathrm{CpG}$ islands in the promoter region of $T L R 2$, and upregulated mRNA and protein levels of TLR2 (35). These previous results demonstrated that hypomethylation of TLR2 promoter CpG islands was able to increase the expression of TLR2 mRNA and protein. The expression of the TLR2 gene will impair vascular endothelial cell repair and release pro-inflammatory cytokines via MyD88/Mal and NF- $\kappa \mathrm{B}$ pathways, including CRP, IL6 and TNF- $\alpha$; these pro-inflammatory cytokines have been reported to be associated with blood pressure (36-39). Therefore, the hypomethylation of the $T L R 2$ promoter may serve a role in the development of $\mathrm{EH}$ by activating pro-inflammatory responses.

In addition, Pearson correlation analysis in the present study suggested that blood pressure was negatively correlated with the methylation level of CpG6. The present results further indicate that TLR2 gene promoter methylation serves a role in the development of EH. However, the present results were in contrast to those from a previous study (9), which reported a positive association between $T L R 2$ gene methylation and DBP. The disparity may be due to different $\mathrm{CpG}$ sites being analyzed in the different studies. In addition, different age ranges, race and inclusion criteria of the samples may have led to the above discrepancy. DNA methylation has been demonstrated to be a possible biomarker of cancer $(40,41)$, and the present study observed that CpG6 methylation exhibited an appropriate threshold value to predict the risk of $\mathrm{EH}$ according to the results of ROC curve analysis. Therefore, the results of the present study may aid the clinical diagnosis and prediction of $\mathrm{EH}$.

$\mathrm{EH}$ is a multifactorial chronic disease; gene-gene and gene-environment interactions contribute to its onset and progression. GMDR is a nonparametric and genetic model-free alternative to linear or logistic regression for detecting and characterizing nonlinear interactions among discrete genetic and environmental factors. GMDR is able to accommodate qualitative and quantitative phenotypes, enhance prediction accuracy, and adjust for discrete and continuous covariates (42); this increases the accuracy of the analysis and means that a more meaningful conclusion may be drawn. In the present study, a significant two-order gene-gene interaction between CpG6 and CpG8 was observed, in addition to a significant five-order gene-environment interaction among smoking, alcohol consumption, CpG6, CpG7 and CpG8, which may contribute to the risk of EH. However, the biological roles of these interactions are unclear, and further investigation is required in future studies.

There are certain limitations to the present study. mRNA and protein expression were not investigated, therefore transcriptomic regulation was not able to be demonstrated. In addition, the analysis of eight $\mathrm{CpG}$ sites may not be representative of the whole gene.

In conclusion, hypomethylation of the TLR2 gene promoter, particularly CpG6, is associated with the risk of EH. In addition, the CpG6 site of TLR2 gene promoter exhibits utility in the diagnosis of EH. The two-order interaction between CpG6 and CpG8, and the five-order interaction among smoking, drinking, CpG6, CpG7 and CpG8, may be associated with EH risk. The present study may provide novel insights into the pathogenesis of EH from an epigenetic aspect.

\section{Acknowledgements}

The present study was supported by the Zhejiang Province Social Development Research Project (grant no. 2016C33178), the K.C. Wong Magna Fund in Ningbo University, Ningbo Social Development Research Project (grant no. 2014C50051), the Ningbo Scientific Innovation Team for Environment Hazardous Factor Control and Prevention (grant no. 2016C51001), the Ningbo Medical Science and Technology Plan Project (grant no. 2013A39), the Outstanding (Postgraduate) Dissertation Growth Foundation of Ningbo University (grant no. py2014015), and the Scientific Research Innovation Foundation of Ningbo University (grant nos. G16097 and G15070).

\section{References}

1. Oliveras A and de la Sierra A: Resistant hypertension: Patient characteristics, risk factors, co-morbidities and outcomes. J Human hypertens 28: 213-217, 2014.

2. Li D, Lv J, Liu F, Liu P, Yang X, Feng Y, Chen G and Hao M: Hypertension burden and control in mainland China: Analysis of nationwide data 2003-2012. Int J Cardiol 184: 637-644, 2015.

3. Virdis A, Dell'Agnello U and Taddei S: Impact of inflammation on vascular disease in hypertension. Maturitas 78: 179-183, 2014.

4. Dinh QN, Drummond GR, Sobey CG and Chrissobolis S: Roles of inflammation, oxidative stress, and vascular dysfunction in hypertension. Biomed Res Int 2014: 406960, 2014.

5. Bautista LE, Vera LM, Arenas IA and Gamarra G: Independent association between inflammatory markers $(\mathrm{C}$-reactive protein, interleukin-6, and TNF-alpha) and essential hypertension. J Hum Hypertens 19: 149-154, 2005.

6. Aliprantis AO, Yang RB, Weiss DS, Godowski P and Zychlinsky A: The apoptotic signaling pathway activated by Toll-like receptor-2. EMBO J 19: 3325-3336, 2000.

7. Medzhitov R, Preston-Hurlburt P, Kopp E,Stadlen A, Chen C, Ghosh S and Janeway CA Jr: MyD88 is an adaptor protein in the hToll/IL-1 receptor family signaling pathways. Mol Cell 2: 253-258, 1998.

8. O'Neill LA and Greene C: Signal transduction pathways activated by the IL-1 receptor family: Ancient signaling machinery in mammals, insects, and plants. J Leukoc Biol 63: 650-657, 1998.

9. Alexeeff SE, Baccarelli AA, Halonen J, Coull BA, Wright RO, Tarantini L, Bollati V, Sparrow D, Vokonas P and Schwartz J: Association between blood pressure and DNA methylation of retrotransposons and pro-inflammatory genes. Int J Epidemiol 42: 270-280, 2013.

10. Marketou ME, Kontaraki JE, Zacharis EA, Kochiadakis GE, Giaouzaki A, Chlouverakis G and Vardas PE: TLR2 and TLR4 gene expression in peripheral monocytes in nondiabetic hypertensive patients: The effect of intensive blood pressure-lowering. J Clin Hypertens (Greenwich) 14: 330-335, 2012.

11. Dange RB, Agarwal D, Teruyama R and Francis J: Toll-like receptor 4 inhibition within the paraventricular nucleus attenuates blood pressure and inflammatory response in a genetic model of hypertension. J Neuroinflammation 12: 31, 2015.

12. Favre J, Musette P, Douin-Echinard V, Laude K, Henry JP, Arnal JF, Thuillez $\mathrm{C}$ and Richard V: Toll-like receptors 2-deficient mice are protected against postischemic coronary endothelial dysfunction. Arterioscler Thromb Vasc Biol 27: 1064-1071, 2007.

13. Mullick AE, Soldau K, Kiosses WB, Bell TA III, Tobias PS and Curtiss LK: Increased endothelial expression of Toll-like receptor 2 at sites of disturbed blood flow exacerbates early atherogenic events. J Exp Med 205: 373-383, 2008. 
14. Edfeldt K, Swedenborg J, Hansson GK and Yan ZQ: Expression of toll-like receptors in human atherosclerotic lesions: A possible pathway for plaque activation. Circulation 105: 1158-1161, 2002.

15. Razin A, Webb C, Szyf M, Yisraeli J, Rosenthal A, Naveh-Many T, Sciaky-Gallili N and Cedar H: Variations in DNA methylation during mouse cell differentiation in vivo and in vitro. Proc Natl Acad Sci USA 81: 2275-2279, 1984.

16. Deaton AM and Bird A: $\mathrm{CpG}$ islands and the regulation of transcription. Genes Dev 25: 1010-1022, 2011.

17. Zhang LN, Liu PP, Wang L, Yuan F, Xu L, Xin Y, Fei LJ, Zhong QL, Huang Y, Xu L, et al: Lower ADD1 gene promoter DNA methylation increases the risk of essential hypertension. PLoS One 8: e63455, 2013.

18. Fan R, Mao S, Zhong F, Gong M, Yin F, Hao L and Zhang L: Association of AGTR1 promoter methylation levels with essential hypertension risk: A Matched Case-Control Study. Cytogenet Genome Res 147: 95-102, 2015.

19. Fan R, Wang WJ, Zhong QL, Duan SW, Xu XT, Hao LM, Zhao J and Zhang LN: Aberrant methylation of the GCK gene body is associated with the risk of essential hypertension. Mol Med Rep 12: 2390-2394, 2015.

20. European Society of Hypertension-European Society of Cardiology Guidelines Committee: 2003 European Society of Hypertension-European Society of Cardiology guidelines for the management of arterial hypertension. J Hypertens 21: 1011-1053, 2003.

21. Perloff D, Grim C, Flack J, Frohlich ED, Hill M, McDonald M and Morgenstern BZ: Human blood pressure determination by sphygmomanometry. Circulation 88: 2460-2470, 1993.

22. Bassil CF, Huang Z and Murphy SK: Bisulfite pyrosequencing. Methods Mol Biol 1049: 95-107, 2013.

23. Mikeska T, Felsberg J, Hewitt CA and Dobrovic A: Analysing DNA methylation using bisulphite pyrosequencing. Methods Mol Biol 791: 33-53, 2011.

24. Beaulieu LM, Lin E, Morin KM, Tanriverdi K and Freedman JE: Regulatory effects of TLR2 on megakaryocytic cell function. Blood 117: 5963-5974, 2011.

25. West XZ, Malinin NL, Merkulova AA, Tischenko M, Kerr BA, Borden EC, Podrez EA, Salomon RG and Byzova TV: Oxidative stress induces angiogenesis by activating TLR 2 with novel endogenous ligands. Nature 467: 972-976, 2010.

26. West AP, Brodsky IE, Rahner C, Woo DK, Erdjument-Bromage H, Tempst P, Walsh MC, Choi Y, Shadel GS and Ghosh S: TLR signalling augments macrophage bactericidal activity through mitochondrial ROS. Nature 472: 476-480, 2011.

27. Speer T, Rohrer L, Blyszczuk P, Shroff R, Kuschnerus K, Kränkel N, Kania G, Zewinger S, Akhmedov A, Shi Y, et al: Abnormal high-density lipoprotein induces endothelial dysfunction via activation of Toll-like receptor-2. Immunity 38: 754-768, 2013.

28. Jones PL, Veenstra GJ, Wade PA, Vermaak D, Kass SU, Landsberger N, Strouboulis J and Wolffe AP: Methylated DNA and $\mathrm{MeCP} 2$ recruit histone deacetylase to repress transcription. Nat Genet 19: 187-191, 1998.

29. Morita S, Takahashi RU, Yamashita R, Toyoda A, Horii T, Kimura M, Fujiyama A, Nakai K, Tajima S, Matoba R, et al: Genome-wide analysis of DNA methylation and expression of microRNAs in breast cancer cells. Int J Mol Sci 13: 8259-8272, 2012.
30. Jones PA and Baylin SB: The fundamental role of epigenetic events in cancer. Nat Rev Genet 3: 415-428, 2002.

31. Liu Y, Liu P, Yang C, Cowley AW Jr and Liang M: Base-resolution maps of 5-methylcytosine and 5-hydroxymethylcytosine in Dahl S rats: Effect of salt and genomic sequence. Hypertension 63: 827-838, 2014.

32. Jones PA and Takai D: The role of DNA methylation in mammalian epigenetics. Science 293: 1068-1070, 2001

33. Shuto T, Furuta T, Oba M, Xu H, Li JD, Cheung J, Gruenert DC, Uehara A, Suico MA, Okiyoneda T and Kai H: Promoter hypomethylation of Toll-like receptor- 2 gene is associated with increased proinflammatory response toward bacterial peptidoglycan in cystic fibrosis bronchial epithelial cells. FASEB J 20: 782-784, 2006

34. Benakanakere M, Abdolhosseini M, Hosur K, Finoti LS and Kinane DF: TLR2 promoter hypermethylation creates innate immune dysbiosis. J Dent Res 94: 183-191, 2015.

35. Yang G, Zhu Y, Dong X, Duan Z, Niu X and Wei J: TLR2-ICAM1-Gadd45 $\alpha$ axis mediates the epigenetic effect of selenium on DNA methylation and gene expression in Keshan disease. Biol Trace Elem Res 159: 69-80, 2014.

36. Sung KC, Suh JY, Kim BS, Kang JH, Kim H, Lee MH, Park JR and Kim SW: High sensitivity C-reactive protein as an independent risk factor for essential hypertension. Am J Hypertens 16: 429-433, 2003.

37. Bautista LE, López-Jaramillo P, Vera LM, Casas JP, Otero AP and Guaracao AI: Is C-reactive protein an independent risk factor for essential hypertension? J Hypertens 19: 857-861, 2001.

38. Chae CU, Lee RT, Rifai N and Ridker PM: Blood pressure and inflammation in apparently healthy men. Hypertension 38: 399-403, 2001

39. Ito H, Ohshima A, Tsuzuki M, Ohto N, Takao K, Hijii C, Yanagawa M, Ogasawara M and Nishioka K: Association of serum tumour necrosis factor-alpha with serum low-density lipoprotein-cholesterol and blood pressure in apparently healthy Japanese women. Clin Exp Pharmacol Physiol 28: 188-192, 2001.

40. Dou CY, Fan YC, Cao CJ, Yang Y and Wang K: Sera DNA Methylation of CDH1, DNMT3b and ESR1 Promoters as Biomarker for the Early Diagnosis of Hepatitis B Virus-Related Hepatocellular Carcinoma. Dig Dis Sci 61: 1130-1138, 2016.

41. Konecny M, Markus J, Waczulikova I, Dolesova L, Kozlova R, Repiska V, Novosadova $\mathrm{H}$ and Majer I: The value of SHOX2 methylation test in peripheral blood samples used for the differential diagnosis of lung cancer and other lung disorders. Neoplasma 63: 246-253, 2016.

42. Lou XY, Chen GB, Yan L, Ma JZ, Zhu J, Elston RC and Li MD: A generalized combinatorial approach for detecting gene-by-gene and gene-by-environment interactions with application to nicotine dependence. Am J Hum Genet 80: 1125-1137, 2007. 